\title{
Optimization Scale Pasteurization of Baobab Juice Using Response Surface Methodology (RSM)
}

\author{
Ndiaye Ndeye Adiara1*, Bassama Joseph², Dieng Modou', N. C. Toure/kane1,3, Montet Didier4 \\ ${ }^{1}$ Graduate School Polytehnique Dakar, Dakar Fann, Senegal \\ ${ }^{2}$ Gaston Berger University of Saint Louis, Senegal \\ ${ }^{3}$ IRESSEF, Institute for Health Research, Epidemiological Surveillance and Training, Diamniadio Dakar, Senegal \\ ${ }^{4}$ Qualisud, Univ Montpellier, CIRAD, Montpellier SupAgro, University of Avignon, University of La Réunion, Montpellier, \\ France \\ Email: ndadiara@hotmail.com
}

How to cite this paper: Adiara, N.N., Joseph, B., Modou, D., Toure/kane, N.C. and Didier, M. (2020) Optimization Scale Pasteurization of Baobab Juice Using Response Surface Methodology (RSM). Food and Nutrition Sciences, 11, 113-122. https://doi.org/10.4236/fns.2020.112010

Received: December 23, 2019

Accepted: February 21, 2020

Published: February 24, 2020

Copyright (c) 2020 by author(s) and Scientific Research Publishing Inc. This work is licensed under the Creative Commons Attribution International License (CC BY 4.0).

http://creativecommons.org/licenses/by/4.0/

\begin{abstract}
The Adansonia digitata L. known as Baobab is the only species present in West Africa and grows wild. All parts of the plant are used by humans. In Senegal, baobab pulp is widely consumed; it is used as raw material in small and medium enterprises (SMEs) for making juices, concentrates, jams, powder. Drinks or juices from baobab are highly appreciated by consumers; however rapid fermentation can happen even after pasteurization that can shorten their shelf-life. A Doehlert experimental design was used to find a good scale of heat treatment ensuring a proper conservation of baobab juice. Results of the experimental design showed that a heat treatment of $80^{\circ} \mathrm{C}$ for 10 min gives a baobab juice with good sanitary quality that meets the international standards.
\end{abstract}

\section{Keywords}

Baobab Juice, Scale of Pasteurization, Doehlert Experimental Plan, Response Surface Method

\section{Introduction}

The baobab (Adansonia digitata L.) is the unique species of the genus Adansonia that grows in West Africa [1]. This tree grows wild in Senegal [2]. The Senegalese Institute of Agricultural Research (ISRA) has defined two main areas producing baobab fruits near the cities of Kaolack and Tambacounda [3]. More dispersed populations of baobab can be found in the regions of Thies, Louga, 
Matam and Saint Louis [4].

Baobab has an immense nutritional potential because it contains macro and micronutrients essential for health [5]. The fruit is consumed in various forms in Africa, particularly in Senegal [6] [7]. All parts of the plant are used in food, cosmetics, handicrafts, traditional medicine [8] [9]. Baobab fruits are rich in dietary fiber, minerals, especially vitamin C [1] [10] and are an important raw material for the fruit processing sector in Senegal. Overall, baobab fruit pulp and seeds contain significant amounts of nutritionally essential minerals but the amounts vary significantly among the different areas [11]. Also, there is a well-developed international trade for $A$. digitata pulp and oil in South Africa and Malawi, where it is mainly traded for use in the food and cosmetic industries [12] [13]. Processing was carried out traditionally by small and medium enterprises (SMEs) or economic interest group (EIG). Several products are obtained: drinks, concentrates, powders, jams. However, during storage fermentation of the products can occur even in pasteurized products, showing a weak thermal inhibition of microbial and enzyme activity. In SMEs, because of the lack of good hygiene practices, small scale processors generally over-pasteurize their products to ensure the shelf-life. This results in products with very low nutritional quality, because main nutrients such as vitamin $\mathrm{C}$ are not thermo-resistant. Using Experimental design can help optimize the heat treatments. The Doehlert experimental design is very useful because it minimizes the number of experimentations, while maintaining a good precision. This experimental design plan distributes the values on a hexagonal surface, which allows giving more strength to one of the variables (horizontal). In our case it was the temperature.

The purpose of this study was to provide a pasteurization level (time/temperature) which will reduce the biological activities in the product while keeping its biochemical and nutritional characteristics. For this, the response surface methodology was used, based on a two-factor Doehlert design [14].

\section{Materials and Methods}

\subsection{Physical and Chemical Analyses}

Some physico-chemical parameters were measured on stages of the manufacture of baobab juice. All reagents used were of analytical grade and were purchased from Sigma (L'Isle d'Abeau, France). Titratable acidity, $\mathrm{pH}$ and dry matter were measured using standard methods [15]. Total titratable acidity was determined with a TitroLine easy titrator (Schott Instruments, Mainz, Germany), using 0.1 $\mathrm{N} \mathrm{NaOH}$ solution. The $\mathrm{pH}$ value was determined using a calibrated $\mathrm{pH}$ meter and dry matter was determined by drying a $5 \mathrm{~g}$ sample at $105^{\circ} \mathrm{C}$ up to constant weight (24 h minimum). Total soluble solids (TSS) content was measured with an Abbe refractometer (Atago, Tokyo, Japan). The total phenolic content was determined with Folin-Ciocalteu reagent, according to the method optimized by 
[16]. Total and reducing sugars were determined using the Luff-Schoorl method [17]. Vitamin C (ascorbic acid) was assessed by high-performance liquid chromatography (HPLC) [18].

\subsection{Preparation of Baobab Juice}

The results of diagnostic methods for the production of baobab juice of a Senegalese company (Figure 1) allowed preparing a standard juice with of water/fruit juice $1 / 6(\mathrm{v} / \mathrm{v})$ sweetened by addition of sugar.

\subsection{Drink Packaging}

Cold pack was performed before pasteurization. The conditioning was carried out in glass bottles of $60 \mathrm{~mL}$ sealed with plastic plug. They were a reference package, the glass being impermeable to oxygen. Before filling, the bottles and caps were disinfected with bleach containing $100 \mathrm{ppm}$ chlorine for $30 \mathrm{~min}$, rinsed and dried. The capsule on one bottle conditioned was pierced at its center to introduce an electrode for measuring the temperature during pasteurization.

\subsection{Drink Pasteurization}

The bottles were fed into a pre heated water bath (polystat, Bioblock Fischer Scientific, France).

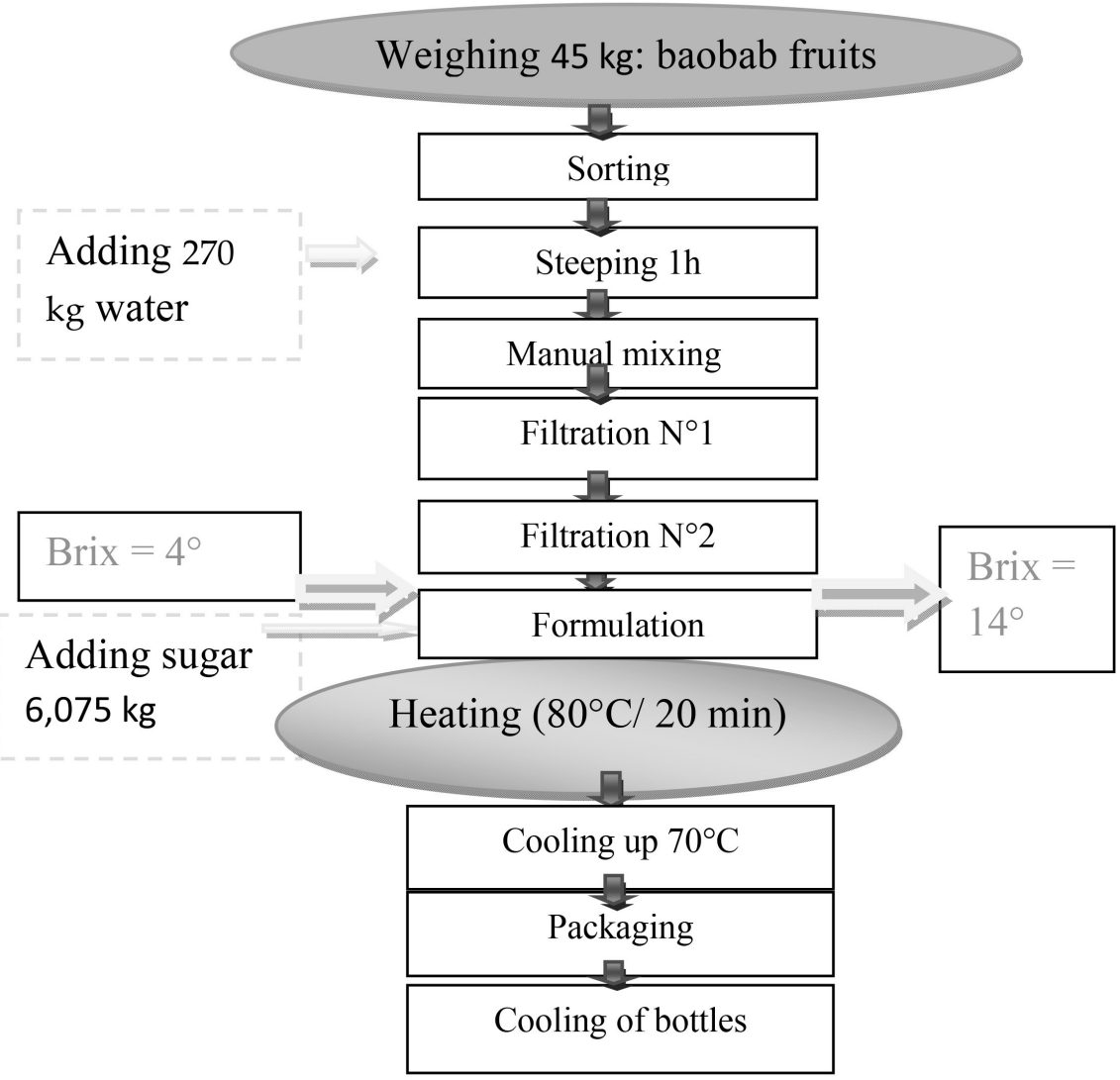

Figure 1. Process flow diagram of baobab juice of some companies in Dakar/Senegal. 
A thermocouple (type K, NiCr-Ni sensor, ref. ZA 9020-FS Thermo E4) of two electrodes was used to measure the temperatures of the water and the product. The thermocouple was connected to a data logger (V2.3 ALMEMO ${ }^{\otimes} 2890-9$, Ahlborn, Holzkirchen, Germany). After application of a scale of pasteurization, the product was cooled in ice water [1].

\subsection{Microbiological Analysis of Pasteurized Products}

Microbiological analyzes were performed on the pasteurized products. The main microorganisms searched were: Total Mesophilic Aerobic Flora (AMTF), yeasts and molds which were found in most the stages of baobab juice processing. Norms, culture media and incubation temperatures used for microbiological analyzes were shown in Table 1.

\subsection{Experimental Design}

Pasteurization parameters were optimized by RSM. For this, the Doehlert plan of two factors was used. The minimum and maximum factors (temperature-time) were fixed in advance. The central point was repeat three times to calculate the error of the equation of the curve. The experimental design obtained shows that the temperatures and times pasteurizers were independent variables. The, AMFT yeasts and molds were the answers from the interaction of the independent variables.

The mathematical model which corresponded to the plan was:

$$
y=a_{0}+a_{1} T+a_{11} T^{2}+a_{2} T p+a_{22} T p^{2}+a_{12} T \times T p
$$

$y$ was the dependent variable (AMFT, yeasts and molds)

$a_{0}$ was the constant

$a_{1}, a_{11}, a_{2}, a_{22}, a_{12}$ were coefficients that represent the linear effects, quadratic independent variables and their interaction, $T$ was the temperature and $T p$ the time.

\subsection{Statistical Analysis}

The analysis of the experimental design and calculation of expected responses were handled by the software Statistica (Statsoft Version 7 USA), as well as the responses to confirm the validity of the plan.

\section{Results}

\subsection{Physicochemical Characteristics}

The physicochemical characteristics of the baobab juice at various stages of the manufacturing process have been reported in the Table 2 .

\subsection{Fitting Model}

Both responses of interest were aerobic mesophilic total flora (AMTF), yeasts and molds. The results of nine trials using the Doehlert plan are shown in Table 3. 
Table 1. Standards and culture media used for microbiological analyzes.

\begin{tabular}{cccc}
\hline Floras & ISO standards & Culture media & $\begin{array}{c}\text { Temperature and duration } \\
\text { of incubation }\end{array}$ \\
\hline AMFT & NF EN ISO 4883 [19] & PCA (Plate Count Agar) & $30^{\circ} \mathrm{C} / 24 \mathrm{~h}$ \\
Yeasts and molds NF EN ISO 7954 [20] & $\begin{array}{c}\text { Sabouraud with } \\
\text { chloramphenicol agar }\end{array}$ & $25^{\circ} \mathrm{C}-30^{\circ} \mathrm{C}$ for 5 days \\
\hline
\end{tabular}

Table 2. Physicochemical characterization of baobab juice samples.

\begin{tabular}{|c|c|c|c|c|c|c|c|c|}
\hline Parameters Samples & $\begin{array}{c}\text { Number of } \\
\text { Samples }\end{array}$ & $\mathrm{pH}$ & TSS & $\begin{array}{l}\text { Titrable acidity } \\
(\mathrm{mEq} / 100 \mathrm{~mL})\end{array}$ & $\begin{array}{l}\text { Total sugar } \\
(\mathrm{g} / 100 \mathrm{~g})\end{array}$ & $\begin{array}{l}\text { Reducing sugar } \\
(\mathrm{g} / 100 \mathrm{~g})\end{array}$ & $\begin{array}{l}\text { Total polyphenol } \\
(\mathrm{g} / 100 \mathrm{~g})\end{array}$ & $\begin{array}{l}\text { Vitamin C } \\
(\mathrm{g} / 100 \mathrm{~g})\end{array}$ \\
\hline Raw material & 5 & $3.55 \pm 0.04$ & - & $136.3 \pm 3.77$ & $34.63 \pm 0.36$ & $5.89 \pm 0.33$ & $3.87 \pm 0.23$ & $340.19 \pm 1.5$ \\
\hline $\begin{array}{l}\text { Unsweetened juice } \\
\text { unpasteurized }\end{array}$ & 3 & $3.22 \pm 0.01$ & 4.00 & $115.65 \pm 0.035$ & $25.54 \pm 0.74$ & $1.401 \pm 0.01$ & $0.27 \pm 0.001$ & $20.00 \pm 0.001$ \\
\hline Sweet juice unpasteurized & 3 & $3.22 \pm 0.01$ & $14 \pm 0.09$ & $94.4 \pm 0.065$ & $23.97 \pm 0.16$ & $1.47 \pm 0.14$ & $0.23 \pm 0.001$ & $13.81 \pm 0.001$ \\
\hline Sweet juice pasteurized & 3 & $3.24 \pm 0.12$ & $14 \pm 0.09$ & $82.98 \pm 0.002$ & $18.96 \pm 0.24$ & $1.61 \pm 0.14$ & $0.19 \pm 0.002$ & $16.47 \pm 0.001$ \\
\hline
\end{tabular}

Table 3. Experimental design essays and corresponding values of the microbiological analysis.

\begin{tabular}{|c|c|c|c|c|}
\hline \multirow{10}{*}{ 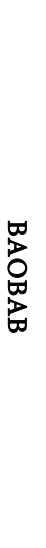 } & Temperature $\left({ }^{\circ} \mathrm{C}\right)$ & Time (min) & AMTF (CFU/mL) & Yeasts \& molds $(\mathrm{CFU} / \mathrm{mL})$ \\
\hline & 40 & $22 ., 5$ & 7545 & 4090 \\
\hline & 52.5 & 7.35 & 6454 & 3727 \\
\hline & 52.5 & 37.66 & 3182 & 3545 \\
\hline & 65 & 22.5 & 3727 & 3663 \\
\hline & 65 & 22.5 & 3818 & 3454 \\
\hline & 65 & 22.5 & 4000 & 3454 \\
\hline & 77.5 & 7.35 & 1727 & 1182 \\
\hline & 77.5 & 37.66 & 121 & 145 \\
\hline & 90 & 22.5 & 53 & 82 \\
\hline
\end{tabular}

The regression from the results of the 7 experimentations (the central point is repeated 3 times) of the Doehlert design was made with the Statistica software. The regression coefficients and the different constants of the mathematical equation of the experimental model for AMFT and yeasts and molds are given in Table 4.

The statistical analysis provided by the plan and those obtained by the experiments results show a perfect match between the model and the observed data, and this was confirmed by the regression coefficient $\mathrm{R}^{2}=0.99$ for the AMFT and 0.97 for the yeasts and molds.

For AMFT variable, the Pareto diagram (Figure 2(a)) showed that the linear effect of the temperature and the linear and quadratic effects of time were significant, whereas the quadratic effect of temperature was not significant on the response AMFT. 
Table 4. Regression coefficients and model parameters for the two dependent variables AMFT and Yeast \& Molds.

\begin{tabular}{ccc}
\hline & \multicolumn{2}{c}{ Depending variables } \\
\cline { 2 - 3 } Model & AMFT & Yeast \& Molds \\
\hline $\boldsymbol{R}^{2}$ & 0.99 & 0.97 \\
$a_{0}$ & 3847.93 & 3523.57 \\
$a_{11}$ & -3795.15 & -2326.93 \\
$a_{2}$ & -24.67 & -718.83 \\
$a_{22}$ & -2439 & -609.5 \\
$a_{12}$ & -1929.2 & -2028.8 \\
\hline
\end{tabular}

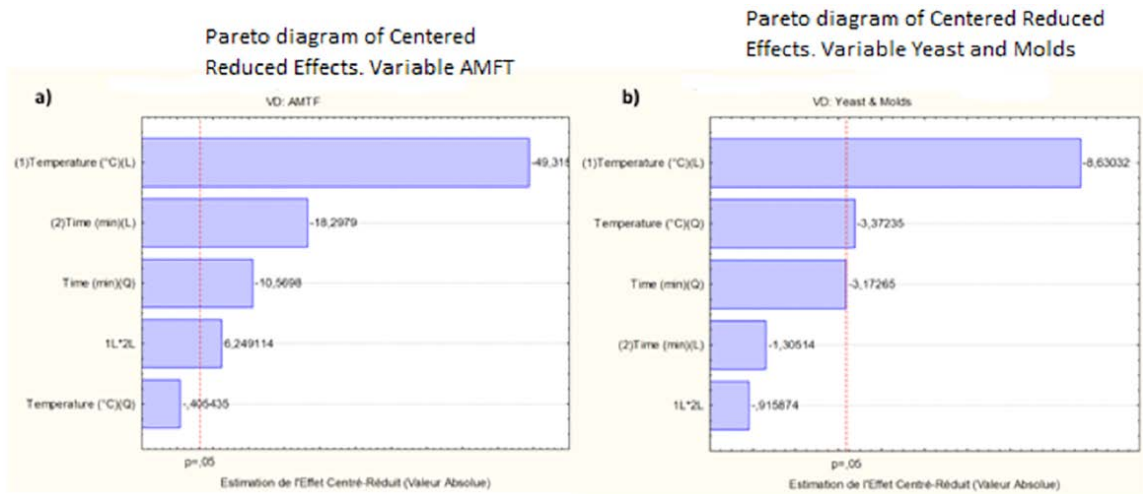

Figure 2. Pareto diagrams showing effects of pasteurization temperature and pasteurization time on (a) AMFT (b) Yeasts and Molds flora.

However, on the yeasts and molds inactivation, the Pareto diagram (Figure 2(b)) showed that only the linear effect of temperature was significant.

The representation in the space (2D) of the surface of the AMFT response versus time and temperature (Figure 3 ) in the frame of the extreme limits of the plan shows the strong effect of temperature/time on the total flora. by calculation, using the obtained equation, it is possible to obtain the temperature/time that permiited to approach zero AMFT.

From the spatial representations obtained (Figure 3 and Figure 4), the time/temperature pairs that gave values less than or equal to 1000 are the best because they meet the standards for yeast and molds. However, for the conservation of micronutrients the best will be the use of high temperatures with short times.

\section{Discussion}

The results of the estimated effects and those obtained by experiments showed that the Doehlert plan chosen was perfectly adequate for this study with regression coefficients $\mathrm{R}^{2}>0.9$.

The outcome of Lee et al. [21] [22] using an experimental model different 


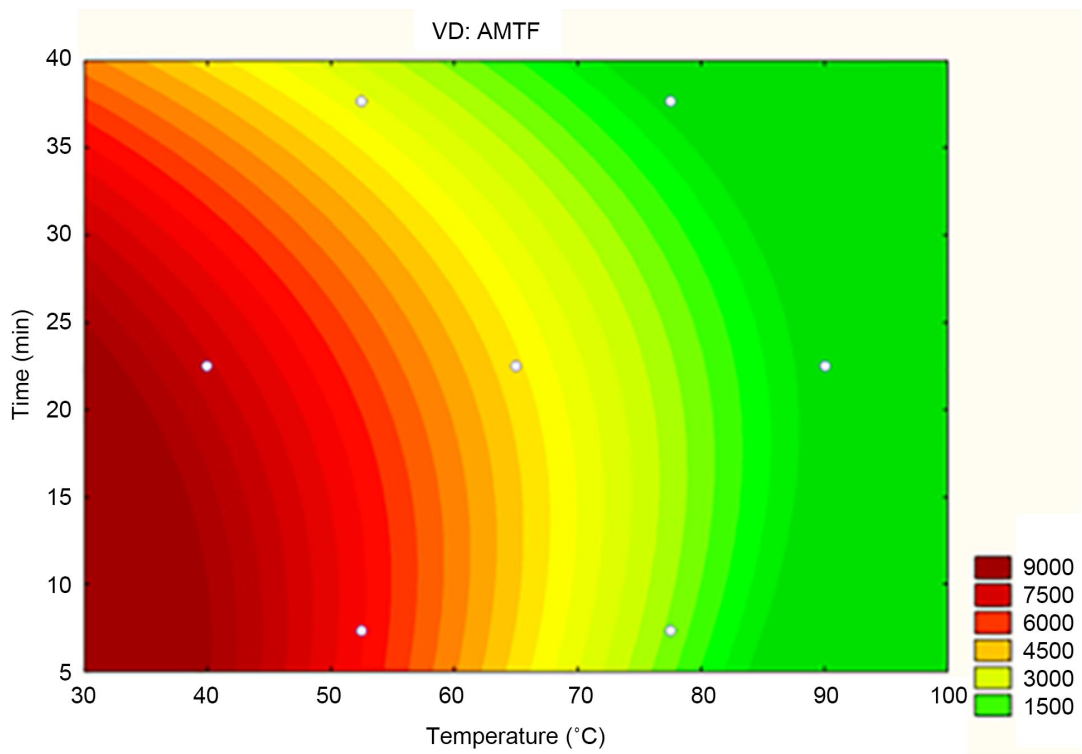

Figure 3. Response surface plots showing effect of temperature and time of pasteurization on AMFT.

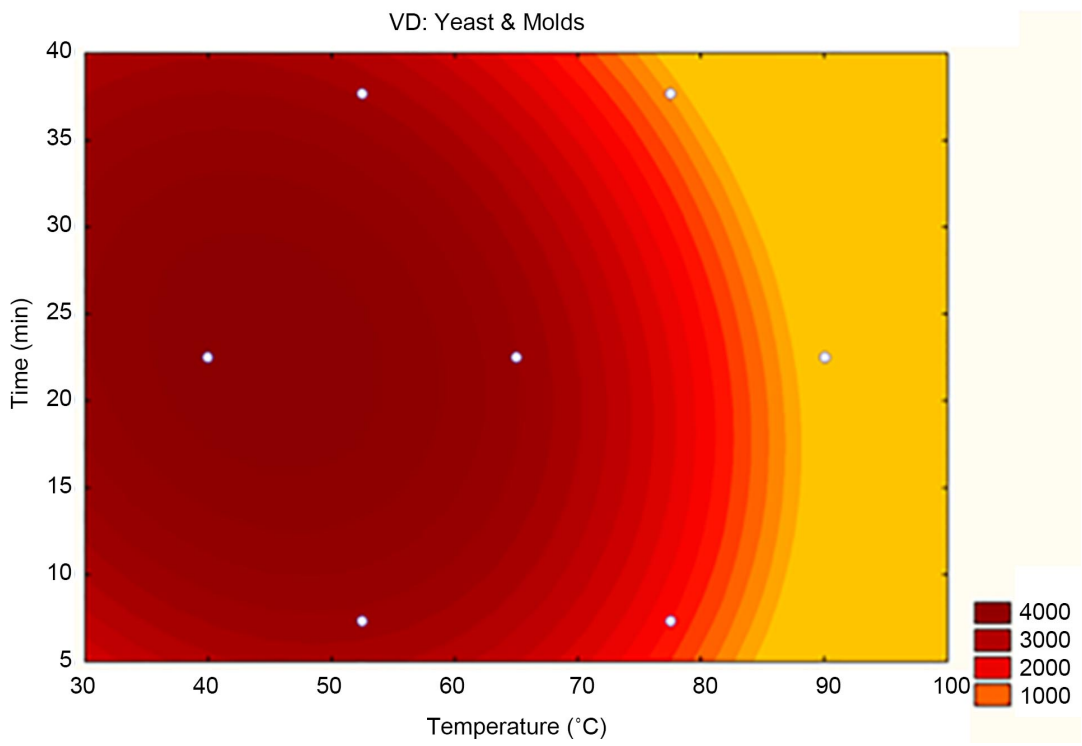

Figure 4. Response surface plots showing effect of temperature and time of pasteurization on Yeasts and Molds.

from Doehlert are confirmed by our study. For this study, the application of a pasteurization of $80^{\circ} \mathrm{C} / 10$ min permitted to optimize the sanitary quality of baobab juice. The work of Bull et al. [23] showed a limited number of yeasts, molds and acetic acid bacteria were able to grow in fruit juice at low $\mathrm{pH}$ (3.3 to 4) as the baobab juice and orange. This study confirms that the temperature of proposed treatment would minimize the contamination of baobab juice for different microorganisms. The level of pasteurization defined by our study was in perfect harmony with the work of. Rodriguez V.M. et al. [24] who showed that the functional properties of pasteurization extracts of Aloe barbadensis Miller 
were optimal at temperatures between $65^{\circ} \mathrm{C}$ and $85^{\circ} \mathrm{C}$ with a time range of 15 to 35 min using Box-Behnken plan.

On one hand, Chen Y. et al. in their study [25] showed that high temperatures of pasteurization were the most efficient to control microbial growth, however they resulted in degradation of phenolic compounds. They also showed that the high temperature treatments have better performance than simple juice on complex viscous juice.

On the other hand Laorko et al. [26] showed that microfiltration, could provide better preservation of physicochemical and taste properties of juice, but especially effective on the inhibition of bacterial growth. Also, according to physicochemical and sensory tests confirmed by many types of research, juices produced by membrane filtration are of an excellent quality. Membrane fouling is a critical issue and inhibits the wider application of membranes in the fruit juice industry [27] [28].

\section{Conclusions}

Microbial contamination of plant products causes a lot of inconvenience to manufacturers. So, the majority of fruit and vegetable juice manufacturers indicated that there was a significant need to control microbial spoilage as part of brand protection. Thus improvement of control over microbial spoilage merits the dedication of resources and, would improve business efficiency by reducing waste. Heat pasteurization is traditionally the most used for the preservation of drinks and juices during storage. Heat treatment of $80^{\circ} \mathrm{C} / 10 \mathrm{~min}$ applied to baobab juice permitted to produce a good hygienic quality juice. However, the application of high temperatures can cause the destruction of some natural nutritional constituents (vitamin C, polyphenols) found in fruits, which are important for health.

To overcome this problem, other non-thermal promising conservation methods are in the process of development for liquid food such as membrane filtration, pulsed electric field, UV radiation ... But these techniques are impractical for small and medium industries in Senegal.

\section{Conflicts of Interest}

The authors declare no conflicts of interest regarding the publication of this paper.

\section{References}

[1] Cisse, M., Sakho, M., Dornier, M., Diop, C.M. and Reyes, M. (2008) Characterization of the Baobab Fruit and Study of Its Transformation into Nectar. Fruits, 64, 19-34. https://doi.org/10.1051/fruits/2008052

[2] Berhaut, J. (1974) Illustrated Flora of Senegal. Volume 2, Clairafrique. Dakar, Senegal.

[3] Samba, S.A.N. (1995) Adansonia digitata, le baobab. Inst Senegal Rearch Agric (ISRA). Dir. Rech, Prod. 
[4] Kerharo, J. and Adam, J.G. (1974) The Traditional Senegalese Pharmacopoeia: Medicinal and Toxic Plants, Vigot Frères.

[5] Kumar, C.M.K., Yugandhar, P. and Savithramma, N. (2016) Biological Synthesis of Silver Nanoparticles from Adansonia digitata L. Fruit Pulp Extract, Characterization, and Its Antimicrobial Properties. Journal of Intercultural Ethnopharmacology, 5, 79-85. https://doi.org/10.5455/jice.20160124113632

[6] Wickens, G. (1982) The Baobabs-Africa's Upside-Down Tree. Kew Bulletin, 37, 173-209. https://doi.org/10.2307/4109961

[7] Diop, A.G., Sakho, M., Dornier, M., Cisse, M. and Reyes, M. (2005) The African Baobab (Adansonia digitata L): Main Characteristics and Uses. Fruits, 61, 55-69. https://doi.org/10.1051/fruits:2006005

[8] Sibibe, M. and William, J.T. (2002) Baobab Adansonia digitata-Fruits for the Future. International Center for Underutilized Crops (ICUC), Southampton.

[9] Codja, J.T.C. and Foton, B.K. (2001) The Baobab, a Multi-Use Species in Benin. International Center for Integrated Eco-Development (CECODI), Cotonou.

[10] Soloviev, P., Niang, T.D., Gaye, A. and Totte, A. (2004) Variability of the Physicochemical Characteristics of the Fruits of Three Woody Picking Species, Harvested in Senegal: Adansonia digitata, Balanites aegytiaca and Tamarindus indica. Fruits, 59, 109-119. https://doi.org/10.1051/fruits:2004011

[11] Muthai, K.U., Karori, M.S., Muchugi, A., Indieka, A.S., Dembele, C., Mng'omba, S. and Jamnadass, R. (2017) Nutritional Variation in Baobab (Adansonia digitata L.) Fruit Pulp and Seeds Based on Africa Geographical Regions. Food Science and $\mathrm{Nu}$ trition, 5, 1116-1129. https://doi.org/10.1002/fsn3.502

[12] Kamatou, G.P.P., Vermaak, I. and Viljoen, A.M. (2011) An Updated Review of Adansonia digitata: A Commercially Important African Tree. South African Journal of Botany, 77, 908-919. https://doi.org/10.1016/j.sajb.2011.08.010

[13] Gebauer, J. and Luedeling, E.A. (2013) Note on the Baobab Adansonia digitata L. in Kordofan, Sudan. Genetic Resources and Crop Evolution. Springer, Science Business Media, Dordrecht. https://doi.org/10.1007/s10722-013-9964-5

[14] Doehlert, D.H. (1970) Uniform Shell Design. Journal of the Royal Statistical Society. Series C (Applied Statistics), 19, 231-239. https://doi.org/10.2307/2346327

[15] AOAC Fruits and Fruits Products (1990) Official Methods of Analysis of the Association of Official Analytical Chemists International. Arlington.

[16] Georgé, S., Brat, P., Alter, P. and Amiot, M.J. (2005) Rapid Determination of Polyphenols and Vitamin C in Plant-Derived Products. Journal of Agricultural and Food Chemistry, 53, 1370-1373. https://doi.org/10.1021/jf048396b

[17] European Economic Community (1979) Determination of Reducing Sugars Expressed as Invert Sugar or Dextrose Equivalent; Luff-Schoorl Method. Official Journal of the European Communities, 239, 41-43.

[18] Dhuique-Mayer, C., Tbatou, M., Carail, M., Caris-Veyrat, C., Dornier, M. and Amiot, M.J. (2007) Thermal Degradation of Antioxidant Micronutrients in Citrus Juice: Kinetics and Newly Formed Compounds. Journal of Agricultural and Food Chemistry, 55, 4209-4216. https://doi.org/10.1021/jf0700529

[19] ISO 4833-2:2013 Microbiology of the Food Chain-Horizontal Method for the Enumeration of Microorganisms-Part 2: Colony Count at 30 Degrees C by the Surface Plating Technique [Internet].

[20] Microbiology Method-General Guidelines for Counting Yeasts and Molds-Colony Counting Technique at $25^{\circ} \mathrm{C}$ (NF ISO 7954-August 1988) [Internet]. 
[21] Lee, W.C., Yusof, S., Hamid, N.S.A. and Baharin, B.S. (2006) Optimizing Conditions for Enzymatic Clarification of Banana Juice Using Response Surface Methodology (RSM). Journal of Food Engineering, 73, 55-63. https://doi.org/10.1016/j.jfoodeng.2005.01.005

[22] Lee, W.C., Yusof, S., Hamid, N.S.A. and Baharin, B.S. (2006) Optimizing Conditions for Hot Water Extraction of Banana Juice Using Response Surface Methodology (RSM). Journal of Food Engineering, 75, 473-479. https://doi.org/10.1016/j.jfoodeng.2005.04.062

[23] Bull, M.K., Zerdin, K., Howe, E., Goicoechea, D., Paramanandhan, P., Stockman, R., et al. (2004) The Effect of High Pressure Processing on the Microbial, Physical and Chemical Properties of Valencia and Navel Orange Juice. Innovative Food Science and Emerging Technologies, 5, 135-149. https://doi.org/10.1016/j.ifset.2003.11.005

[24] Rodríguez-G, V.M., Femeniab, A., González-Laredoa, R.F., Rocha-Guzmána, N.E., Gallegos-Infantea, J.A., Candelas-Cadilloc, M.G., Ramírez-Bacac, P., Simalb, S. and Rosselló, C. (2011) Effects of Pasteurization on Bioactive Polysaccharide Acemannan and Cell Wall Polymers from Aloe barbadensis Miller. Carbohydrate Polymers, 86, 1675-1683. https://doi.org/10.1016/j.carbpol.2011.06.084

[25] Chen, Y., Yu, L.J. and Rupasinghe, H.V. (2013) Effect of Thermal and Non-Thermal Pasteurisation on the Microbial Inactivation and Phenolic Degradation in Fruit Juice: A Mini-Review. Journal of the Science of Food and Agriculture, 93, 981-986. https://doi.org/10.1002/jsfa.5989

[26] Laorko, A., Tongchitpakdee, S. and Youravong, W. (2013) Storage Quality of Pineapple Juice Non-Thermally Pasteurized and Clarified by Microfiltration. Journal of Food Engineering, 116, 554-561. https://doi.org/10.1016/j.jfoodeng.2012.12.033

[27] Urošević, T., Povrenović, D., Vukosavljević, P., Urošević, I. and Stevanović, S. (2017) Recent Developments in Microfiltration and Ultrafiltration of Fruit Juices. Food and Bioproducts Processing, 106, 147-161. https://doi.org/10.1016/j.fbp.2017.09.009

[28] Paraskeva, P. and Graham, N.J.D. (2005) Treatment of a Secondary Municipal Effluent by Ozone, UV and Microfiltration: Microbial Reduction and Effect on Effluent Quality. Desalination, 186, 47-56. https://doi.org/10.1016/j.desal.2005.04.057 